\title{
The Economics of Professional Boxing Contracts
}

\author{
Rafael Tenorio \\ Department of Economics \\ DePaul University \\ 1 E. Jackson Blvd. - Suite 6200 \\ Chicago, IL 60604-2287 \\ rtenorio@condor.depaul.edu \\ (312) 362-8309 (Phone) \\ (312) 362-5452 (Fax)
}

I thank Gabriella Bucci, Ralph Chami, Tom Cosimano, Joe Harrington, Jr., Gregg Hess, Eric Rasmusen, Jim Ratliff, Rich Sheehan, and various workshop participants for comments and suggestions. Detailed comments of two anonymous referees also helped me improve the paper a great deal. I remain responsible for any mistakes or shortcomings. 


\title{
The Economics of Professional Boxing Contracts
}

\begin{abstract}
This paper analyzes the characteristics and incentive effects of contractual practices in professional boxing. A boxer's "purse" is linked to past rather than contemporaneous performance, thereby creating an incentives problem. Although consumption smoothing considerations alleviate this problem, savings act as further insurance and the likelihood of moral hazard increases. Observation of a boxer being poorly prepared for a fight after earning a very large purse is consistent with this prediction. These disappointing outcomes are likely driven by the absence of a strategic principal in the boxing market, and by the prevalence of "casual" boxing fans.
\end{abstract}

JEL Classification: L83, J41, D91

Key words: professional boxing, contracting, intertemporal decisions 


\section{Introduction}

On October 25, 1990, James "Buster" Douglas was scheduled to defend his heavyweight boxing title against Evander "Real Deal" Holyfield. Douglas, who was guaranteed over \$20 million for the match, showed up visibly out of shape, and delivered a lackluster performance while being knocked-out in three rounds. He did not fight again for six years. Many boxing fans felt ripped-off by Douglas' performance. From the fans' perspective, the contract Douglas was given did not elicit appropriate work incentives.

Unlike other individual sports, where explicit incentive payments and rank-order rewards are pervasive, professional boxing displays a simple yet unique compensation scheme: a boxer's payment or "purse" for a given fight is entirely guaranteed. Once a fight's expected proceeds are assessed, and after deducting administrative costs, the boxer knows exactly how much he will get for his performance, win, lose, or draw, thereby enjoying full insurance at any given fight. ${ }^{1}$ Economic theory predicts that, once fully insured, an agent will not exert the proper effort level, i.e., there will be moral hazard. Thus, in a one-shot case, this contract does not give the boxer an incentive to train properly, increasing the likelihood of a poor showing.

How do incentives work in professional boxing? The answer lies in the dynamic nature of boxing's contractual arrangements. The market value of a fight, which is the source of the boxers' payments, is largely determined by the boxers' reputations. Thus, although in a static setting one would expect a sub-par performance, such a performance would have a detrimental effect on a boxer's future rewards. As a result, the boxer faces a trade-off between the disutility of effort expended in training for a fight and the positive effect that this effort has on his future payments, income, and consumption. Therefore, professional boxing contractual incentives work through 
intertemporal incentives.

Intertemporal agency issues have been extensively studied. Fama (1980) asserts that market forces will tend to remove moral hazard problems because workers will be concerned about their labor market reputations. Klein and Leffler (1981) and Shapiro (1982) apply a similar logic to product markets, and show that firms will have the incentive to supply good quality products when future sales depend on their reputations. Thus, this approach suggests that explicit contracts may not be necessary, since markets are capable of providing efficient implicit contracts. However, Holmström (1982) shows that only under very specific assumptions will this claim be valid. In environments with discounting, risk-averse agents, and non-linear technologies, the market's ability to effectively police incentives may be limited.

Radner (1981, 1985) and Rubinstein and Yaari (1983) show that multi-period explicit contracting can approach first-best outcomes only if the horizon is sufficiently long and discount factors are high. ${ }^{2}$ Lambert (1983) relaxes these two assumptions within a two-period model and shows that although incentive problems cannot be eliminated, they can be alleviated if rewards are based on all information available at each period. Moreover, the nature of multi-period contracting changes if credit markets are accessible (Rogerson 1985, Fudenberg et. al. 1985, Allen 1986). Since saving and borrowing render the consumption-smoothing role of a multi-period contract redundant, the principal loses some handle in the provision of incentives, and second-best outcomes are no longer attainable. Rogerson shows that because saving provides additional insurance to a risk-averse agent, she will prefer to save part of her current wage if she could. ${ }^{3}$ Thus, shirking is more likely in these cases.

Although some of the features of the existing models apply to professional boxing, there is an 
element that makes contracting in this market unique: a true principal --one that optimizes strategically against the agent-- does not exist. The boxer's manager and the fight promoter play mainly intermediation roles, and as such their interests are not opposed to those of the boxer. The absence of a strategic principal offers an initial explanation for the potential suboptimality of these contracts: by not tying current compensation to current performance, valuable information is excluded. As shown by Holmström (1979), and Shavell (1979), current output can be omitted in the writing of the contract only if past output is a sufficient statistic for current effort, which is obviously not the case in boxing.

The principal's role in the boxing market is played by a large and decentralized group of boxing fans or "fight buyers" who do not coordinate their actions. As the theory shows, since each fan's decision about buying the fight has a negligible effect on the boxer's payment, the resulting choice may be myopic. An indication of this may be the observed "short-term memory" of fans: a good performance can easily erase a stream of poor performances and vice versa. The Hollywood saying "you are only as good as your last performance" seems to fit perfectly to boxing. ${ }^{4}$

The goal of this paper is to analyze the existing contractual arrangements in professional boxing with emphasis on two questions. First, what are the effects that standard boxing contracts have on a boxer's intertemporal choice of effort? Second, what sort of fan behavior is consistent with the existing structure of boxing contracts? ${ }^{5}$

The analysis is based on a multi-period model incorporating standard features of professional boxing. In the model, a boxer's future reward is a function of his current performance, and this performance is positively but not deterministically related to the effort he expends training for a fight. Since effort is costly and the boxer cares about consumption smoothing, the payment scheme 
presents him with a tradeoff: higher effort causes current disutility but has a positive impact on expected income and consumption. In principle, as in reputation models, market forces should provide the boxer with the incentives to train well. However, unlike the standard models, the boxer's access to saving distorts the incentives provided by repetition. If accumulated savings are high enough, a boxer may find it optimal to exert arbitrarily low effort at some point in time and either retire permanently, or quit temporarily and stage a comeback later, exploiting the fans short-term memory. This is consistent with the common observation of a lackluster performance induced by poor preparation following a large payday.

The paper also presents some suggestive evidence lending support to a wealth-disincentive effect in professional boxing. Comparative analysis of an extensive sample of boxing champions across categories reveals that heavier-weight champions wait longer between title defenses and make fewer successful defenses per year than lower-weight champions. Since, on average, championship purses are higher for heavier weight classes, these observations are consistent with the theoretical prediction.

A second point I discuss is the type of fan behavior reconcilable with the observed contractual practices and the relationship between the fans' assessments and the purses offered to boxers. I argue that the observation of large purses followed by disappointing performances is compatible with the predominance of "casual" fans. A casual fan is defined as one who fails to account for the disincentive effect of large purses on the boxer's effort when deciding on his willingness to pay for a fight. If a promoter believed that most fans were "avid" or knowledgeable (able to anticipate this moral hazard), excessively large purses would not exist in equilibrium because they would bias the promoter's payoff downwards. 
The rest of the paper is as follows. Section II describes boxing's standard contractual practices. Section III discusses behavior reconcilable with observed outcomes in this market. Section IV characterizes a boxer's intertemporal decisions. Section V analyzes the relationship between fans' assessments and boxers' purses. Some empirical implications are discussed in section VI. Section VII presents conclusions.

\section{Describing a Boxing Contract}

(a) The market value of a fight

Boxers A and B will engage in a match at time t. A's guaranteed payment or "purse" is $\mathrm{w}_{t}$, while B's is $\mathrm{v}_{\mathrm{t}}$. In exchange, both boxers will deliver their performances, which will be represented by the nonnegative indices $x_{t}(A)$ and $y_{t}(B)$. Purses are determined on the basis of the fight's expected revenue. This expected revenue or "market value" is an estimate of the total willingness to pay from the "fight buyers", i.e., the viewers, advertisers, and other interested parties. ${ }^{6}$ Since the bulk of these revenues is generated by viewing fees, I will henceforth assume that this is the only revenue source.

Although alternative outlets are available for viewing the fight, I abstract from pricing issues, and assume that each viewer pays a uniform fee $\varphi t^{7}$ An individual's willingness to pay is determined by his expected utility from viewing the match. This utility is a function of the boxers' expected performances, and each agent forms his expectations based on his information and an idiosyncratic or "opinion" factor. Individual i's information set, denoted $\mathrm{I}_{\mathrm{t}}$, includes all relevant information about the fight at $t$, like the boxers' reputations, purses and other elements. Since a good deal of this information is public, $\mathrm{I}_{\mathrm{t}}$ should not systematically differ across individuals. Reputations 
are built over time, and thus they depend on the boxers' past performances. The opinion factor $\theta_{\text {it }}$ may reflect i's ability to process information as well as other subjective considerations. We can summarize i's willingness to pay for the fight and his information set as:

$$
\begin{aligned}
& \mathrm{p}_{\mathrm{it}}=\mathrm{g}\left[\mathrm{E}\left(\mathrm{x}_{\mathrm{t}}, \mathrm{y}_{\mathrm{t}}\right) \mid\left(\mathrm{I}_{\mathrm{t}}, \theta_{\mathrm{it}}\right)\right], \text { and } \\
& \mathrm{I}_{\mathrm{t}}=\left\{\mathrm{X}_{\mathrm{t}}, \mathrm{Y}_{\mathrm{t}}, \mathrm{W}_{\mathrm{t}}, \mathrm{V}_{\mathrm{t}}, \omega_{\mathrm{t}}\right\},
\end{aligned}
$$

where $p_{\text {it }}$ denotes i's willingness to pay, $\mathrm{E}[\cdot \mid \cdot]$ denotes conditional expectation, $\mathrm{X}_{\mathrm{t}}=\mathrm{X}_{\mathrm{t}}\left(\mathrm{x}_{\mathrm{t}-1}, \mathrm{X}_{\mathrm{t}-2}, \ldots, \mathrm{X}_{1}\right)$ and $\mathrm{Y}_{\mathrm{t}}=\mathrm{Y}_{\mathrm{t}}\left(\mathrm{y}_{\mathrm{t}-1}, \mathrm{y}_{\mathrm{t}-2}, \ldots, \mathrm{y}_{1}\right)$ denote the boxers' reputations, and $\omega_{\mathrm{t}}$ represents any other relevant information or "news" about the fight.

Individual $\mathrm{i}$ will pay for viewing the fight if $\mathrm{p}_{\mathrm{it}} \geq \varphi \mathrm{t}$. Suppose there are $\mathrm{n}$ individuals for whom this inequality holds. Then, the fight's market value $m_{t}$ is an estimate of $n$ multiplied by $\varphi t$. In practice, a large fraction of $n$--and $m_{t}--$ can be assessed ex-ante. This is because viewing fees may be pre-contracted in blocks and on-site proceeds are largely determined by capacity. Other revenue components like pay-per-view or closed-circuit fees can also be estimated, but their totals will not be known until after the fight. Assuming that the opinion and news variables are independently distributed with zero mean each, $\mathrm{m}_{\mathrm{t}}$ can be decomposed into a predictable $\left(\mathrm{m}_{\mathrm{t}}\right)$ and a random $\left(\mu_{\mathrm{t}}\right)$ component:

$$
\mathrm{m}_{\mathrm{t}}=\mathrm{n}\left(\varphi_{\mathrm{t}}\right) \varphi_{\mathrm{t}}=\overline{\mathrm{m}}_{\mathrm{t}}\left(\mathrm{X}_{\mathrm{t}}, \mathrm{Y}_{\mathrm{t}}, \mathrm{W}_{\mathrm{t}}, \mathrm{V}_{\mathrm{t}}\right)+\mu \mathrm{t}
$$

where $\mu \approx\left(0, \sigma_{\mu}{ }^{2}\right)$.

The fight promoter would then assess the expected value of (2), and based on that decide on the purses he will guarantee to each boxer, ${ }^{8}$ i.e., for boxer B:

$$
\mathrm{v}_{\mathrm{t}}=\mathrm{v}_{\mathrm{t}}\left(\mathrm{X}_{\mathrm{t}}, \mathrm{Y}_{\mathrm{t}}, \mathrm{w}_{\mathrm{t}}, \mathrm{v}_{\mathrm{t}}\right)
$$

From (3a) it is clear that, given an opponent and the opponent's reputation and purse, B is able 
to influence his purse at $\mathrm{t}$ only through building his reputation up to that period. ${ }^{9}$ Hence, omitting predetermined terms, $(3 a)$ is rewritten as:

$$
\mathrm{v}_{\mathrm{t}}=\mathrm{v}_{\mathrm{t}}\left[\mathrm{Y}_{\mathrm{t}}\left(\mathrm{X}_{\mathrm{t}}, \mathrm{w}_{\mathrm{t}}\left(\mathrm{X}_{\mathrm{t}}\right)\right)\right]
$$

Since the focus is on B, I will henceforth omit the conditioning arguments in (3b), and implicitly understand that B's reputation affects his purse at $\mathrm{t}$ for given $\left(\mathrm{X}_{\mathrm{t}}, \mathrm{W}_{\mathrm{t}}(\cdot)\right)$. Thus, using the definition of B's reputation, (3b) becomes:

$$
\mathrm{v}_{\mathrm{t}}=\mathrm{v}_{\mathrm{t}}\left(\mathrm{y}_{\mathrm{t}-1}, \mathrm{y}_{\mathrm{t}-2}, \ldots, \mathrm{y}_{1}\right),
$$

where $\mathrm{v}_{\mathrm{t}}$ is increasing in all its arguments.

(b) The boxer's performance index and utility function

B's performance is a function of his training effort:

$$
y_{t}=f\left(e_{t}\right)+\varepsilon t
$$

where $y_{t} \geq 0$ is $B$ 's output or performance index, $e_{t} \in\left[0, e^{*}\right]$ is B's effort level, $f^{\prime}>0 \geq f^{\prime \prime}, f(0)=0$, and $\varepsilon_{t}$ is i.i.d. over time with variance $\sigma_{\varepsilon}^{2} .{ }^{10}$ B's effort can be interpreted as the number of hours he trains every day, i.e., $\mathrm{e}^{*}=24$. The term $\varepsilon$ t summarizes any uncontrollable factors that may affect B's observed performance, or can also be interpreted as a measurement error. The index $\mathrm{y}_{\mathrm{t}}$, which is assumed continuous, does not reflect victory or defeat but rather indicates the quality of the fighter's performance. Victory or defeat are a function of the interaction of $\mathrm{x}_{\mathrm{t}}$ and $\mathrm{y}_{\mathrm{t}}$.

As is standard in a problem like this, the distribution of $\varepsilon_{t}$ induces a cumulative distribution of output $H\left(e_{t}, \varepsilon t\right)$ that increases in $e_{t}$ in a first-order stochastic dominance sense. Thus, higher effort by B shifts the output distribution making it more likely that his performance will be indexed higher. Because effort is unobservable, B's payment cannot depend on $e_{t}$ but only on $y_{t}$, and the accuracy of 
$\mathrm{y}_{\mathrm{t}}$ as a signal will depend on $\sigma_{\varepsilon}^{2}$.

Finally, assume that B's one-period utility is a function of the effort he expends preparing for the fight $\left(\mathrm{e}_{\mathrm{t}}\right)$ and his consumption during that period $\left(\mathrm{c}_{\mathrm{t}}\right)$ :

$$
\mathrm{U}^{\mathrm{b}}{ }_{\mathrm{t}}=\mathrm{U}^{\mathrm{b}}{ }_{\mathrm{t}}\left(\mathrm{c}_{\mathrm{t}}, \mathrm{e}_{\mathrm{t}}\right) \text {, }
$$

where $\mathrm{U}^{\mathrm{b}}{ }_{\mathrm{t} 1}>0>\mathrm{U}^{\mathrm{b}}{ }_{\mathrm{t} 2}$, and $\mathrm{U}^{\mathrm{b}}{ }_{\mathrm{t} 22}<0>\mathrm{U}^{\mathrm{b}}{ }_{\mathrm{t} 11}, \forall \mathrm{c}_{\mathrm{t}}, \mathrm{e}_{\mathrm{t}} \geq 0$, and the subscripts 1 and 2 denote partial derivatives with respect to consumption and effort. ${ }^{11}$

\section{Strategic Behavior in Professional Boxing}

At each period t, the game in the boxing market unfolds as follows:

(i) The promoter: (a) determines the viewing fee $\varphi t$ and assesses the fight's ex-ante market value $\mathrm{m}_{\mathrm{t}}$, and (b) offers the boxers the guaranteed purses $\mathrm{w}_{\mathrm{t}}$ and $\mathrm{v}_{\mathrm{t}}$.

(ii) Each fight buyer, given his information set $I_{t}$, chooses whether or not to pay $\varphi_{t}$ for viewing the fight.

(iii) Each boxer, given his current purse and previously accumulated assets chooses his effort and consumption levels $e_{t}$ and $c_{t}$.

The fans' purchasing decisions determine the fight's ex-post market value and the promoter's payoff. After the boxers make their effort-consumption decisions, the fight takes place and each fan receives his payoff as the difference between his utility from the boxers' performances and the viewing fee. Note that since the promoter simply offers the market schedule, the game is between the fight buyers and the boxers. Concentrating on B, this game is one in which a single long-run "big" player (B) faces a large number of (overlapping) long-run "small" players (the fans). As shown in the game-theoretic literature, in this setup the small players always play short-run best 
responses to the anticipated play of their opponents. ${ }^{12}$ This is because the small players are anonymous, and each player only observes the play of the big player and possibly the play of subsets of other small players.

This problem is similar in structure to that of a seller whose reputation --and sales-- depends on his past choice of product quality (Klein and Leffler 1981, Shapiro 1982). Here, a cooperative outcome in which the seller always offers good quality and the buyers always buy the product, is attainable through repeat purchases. Buyers buy in the current period as long as past quality was good, and boycott as soon as quality deteriorates. The seller finds it optimal to offer good quality because the one-period windfall he would get from offering bad quality would be offset by the future losses triggered by the consumers' boycott. In this reputation equilibrium buyers correctly expect good quality because it is in the seller's best interest to supply this quality. Since expectations are self-fulfilling, this is a "bootstrapping" equilibrium.

This reputation equilibrium is in principle attainable in boxing. A boxer would have the incentive to train hard because this will positively impact his future rewards. Fans know that training hard is in the boxer's best interest and thus they would buy the fight based on this expectation. If it was obvious that the boxer shirked, fans would punish him by not buying his next fight(s), and would not resume their purchases until the boxer rebuilds his reputation with one or more good performances. If the punishment is set correctly, shirking will not occur in equilibrium and expectations will be fulfilled.

However, as stressed before, outcomes with non-self-fulfilling expectations are common in professional boxing. Why are these outcomes admissible? I subsequently discuss some possible explanations. 
A first reason may be that boxing fans are too forgiving and do not punish defections harshly enough. As shown in reputation models, if a player finds it optimal to build a reputation and then milk it, cooperation is not sustainable in equilibrium. If fans display short-term memory and only punish defections for one (or a few) period(s), a boxer may find it optimal to shirk. The subsequent section of this paper shows that shirking may be more likely once the boxer's savings are high enough to afford him to rebuild his reputation while consuming mainly out of his savings.

A second explanation is a one-sided version of the "end-game" problem. Although from the fans' perspective, the probability that a boxer will retire increases as he gets older, only the boxer knows when this will happen. Thus, even if a reputation equilibrium is being played, it is possible that the boxer will end the game unilaterally and defect in his last fight. Since no punishment is possible afterwards, this behavior is optimal. Like before, defection is more likely if the boxer's savings are high enough. ${ }^{13}$

Third, cooperation may be hindered by noisy observability and lack of monitoring. Since performance is not a deterministic function of effort, and effort is unobservable, fans may give the boxer the benefit of the doubt after a bad performance. As a result, either no punishment will take place or it may be triggered only after two or more defections. If the boxer knows this, opportunism is optimal. Radner (1981, 1985) and Rubinstein and Yaari (1983) discuss contract design under these conditions.

A fourth possible explanation is incomplete information about the boxer's "type" or private attributes. Suppose that boxers can be one of two types, honest or opportunistic. Honest boxers always cooperate while opportunistic boxers are strategic. As shown by Kreps et. al. (1982), if fans face uncertainty about the true type of the boxer, opportunistic boxers may pool with honest boxers 
for a number of periods and then defect and supply low effort(s) as the end of the game nears.

Finally, it is possible that fight buyers do not use available information strategically, or lack the necessary information to devise fully rational strategies. ${ }^{14}$ For instance, if fans are not aware of purses or are unable to anticipate the disincentive effects of large purses or large savings accounts, disappointment may occur. Also, boxers have private information about their savings and effort-consumption tradeoffs, which are crucial in determining optimal choices. The effects of the fans' potential inability to process information correctly are analyzed in section $\mathrm{V}$.

\section{The Boxer's Problem}

As suggested in the previous section, the fans' short-term memory could explain why the expectations about a boxer's effort may not be self-fulfilling. In this section I assume that fans display short-term memory and characterize the boxers' optimal effort-consumption decisions under these conditions.

Like before, assume that at time $t$ the promoter offers $B$ the purse $v_{t}$. Fans have short-term memory and base their expectations about B's current performance on B's performance at $\mathrm{t}-1$. A possible explanation for this is that the time elapsed between fights is relatively long, so that only B's performance at $\mathrm{t}-1$ stays in the fans' memories at $\mathrm{t} .{ }^{15}$ This amounts to a payment scheme of the form:

$$
\mathrm{V}_{\mathrm{t}}=\left\{\mathrm{v}_{\mathrm{t}}\left(\mathrm{y}_{\mathrm{t}-1}\right), \mathrm{v}_{\mathrm{t}+1}\left(\mathrm{y}_{\mathrm{t}}\right), \ldots\right\}
$$

Consider an additive separable version of the boxer's one-period utility defined in (5):

$$
\mathrm{U}_{\mathrm{t}}^{\mathrm{b}}\left(\mathrm{c}_{\mathrm{t}}, \mathrm{e}_{\mathrm{t}}\right)=\mathrm{u}\left(\mathrm{c}_{\mathrm{t}}\right)-\mathrm{d}\left(\mathrm{e}_{\mathrm{t}}\right),
$$

where both $\mathrm{u}(\cdot)$ and $\mathrm{d}(\cdot)$ are assumed to be time-invariant and twice continuously differentiable with $\mathrm{u}^{\prime}>0>\mathrm{u}^{\prime \prime} \forall \mathrm{c}_{\mathrm{t}} \geq 0$, and $\mathrm{d}^{\prime}>0<\mathrm{d}^{\prime \prime} \forall \mathrm{e}_{\mathrm{t}} \geq 0$. Further assuming that utility is also time-separable and that 
future utilities are discounted using the factor $\beta \in(0,1)$, B's discounted stream of expected utilities is: 16

$$
\mathrm{EU}^{\mathrm{b}}=\sum_{\mathrm{t}=1, \ldots, \infty} \mathrm{E}_{\mathrm{t}}\left[\mathrm{u}\left(\mathrm{c}_{\mathrm{t}}\right)-\mathrm{d}\left(\mathrm{e}_{\mathrm{t}}\right)\right] \beta^{\mathrm{t}-1}
$$

If $B$ can save and borrow at a risk-free rate $r$, his problem is:

$$
\begin{aligned}
& \operatorname{Max} \mathrm{EU}^{\mathrm{b}} \\
& \left\{\mathrm{c}_{\mathrm{t}}, \mathrm{e}_{\mathrm{t}}\right\}_{\mathrm{t}=1, \ldots, \infty}
\end{aligned}
$$

\section{s. t.}

$$
\begin{aligned}
& \mathrm{c}_{\mathrm{t}}+\mathrm{S}_{\mathrm{t}}=\mathrm{v}_{\mathrm{t}}\left[\mathrm{f}\left(\mathrm{e}_{\mathrm{t}-1}\right)+\varepsilon_{\mathrm{t}-1}\right]+\mathrm{Rs}_{\mathrm{t}-1} \\
& \mathrm{v}_{1}=\mathrm{v}_{1} \\
& \lim _{\mathrm{t} \rightarrow \infty} \mathrm{E}_{\mathrm{t}} \beta^{\mathrm{t}-1} \mathrm{~S}_{\mathrm{t}}=0 \\
& \mathrm{c}_{\mathrm{t},} \mathrm{e}_{\mathrm{t}} \geq 0
\end{aligned}
$$

where $\mathrm{S}_{\mathrm{t}}$ denotes savings at period $\mathrm{t}, \mathrm{R}=1+\mathrm{r}$ is the exogenous gross return on savings, and $\mathrm{Rs}_{\mathrm{t}-1} \equiv \mathrm{S}_{\mathrm{t}}$ is the value of B's gross savings at the beginning of t. Equation (9b) says that B's assets consist of his current payment and the current value of his past savings, and that these assets are either devoted to consuming or further saving. Expressions (9c), (9d), and (9e) specify the boxer's first professional purse, boundary condition on savings, and non-negativity of $c_{t}$ and $e_{t}{ }^{17}$

This problem resembles the one analyzed by Yaari (1976) in his work on intertemporal consumption under uncertainty. The main difference is that in Yaari's model the individual's intertemporal incomes are i.i.d. random variables, while here the individual exercises some control over his income stream with his effort choice. From Yaari's work we know that when future income is uncertain a risk-averse individual's optimal consumption policy involves a marginal propensity to consume smaller than one, i.e., the individual saves a positive amount each period. Rogerson (1985) 
also showed that in repeated agency where a risk-averse agent's future payments are stochastic, he will always choose to save part of his current earnings. In both cases, saving is an income transfer to the future that acts as insurance.

The following proposition characterizes B's optimal decisions when the non-negativity constraints on consumption and effort do not bind: ${ }^{18}$

Proposition 1: If the constraints (9e) do not bind, the dynamic program defined in (9a)-(9e) has a unique interior solution defined by the time-invariant policies $\left\{\mathrm{c}_{\mathrm{t}}{ }_{\mathrm{t}}\left[\mathrm{S}_{\mathrm{t}}, \mathrm{V}_{\mathrm{t}}(\cdot)\right], \mathrm{e}_{\mathrm{t}}{ }_{\mathrm{t}}\left[\mathrm{S}_{\mathrm{t}}, \mathrm{V}_{\mathrm{t}}(\cdot)\right]\right\}$. These policies satisfy the stochastic Euler conditions:

$$
\begin{aligned}
& \mathrm{u}^{\prime}\left(\mathrm{c}_{\mathrm{t}}^{*}\right)=\beta \mathrm{RE}_{\mathrm{t}}\left[\mathrm{u}^{\prime}\left(\mathrm{c}_{\mathrm{t}+1}^{*}\right)\right], \text { and } \\
& \mathrm{d}^{\prime}\left(\mathrm{e}^{*}{ }_{\mathrm{t}}\right)=\beta \mathrm{E}_{\mathrm{t}}\left[\mathrm{u}^{\prime}\left(\mathrm{c}_{\mathrm{t}+1}^{*}\right) \mathrm{v}^{\prime} \mathrm{t}+1\left(\mathrm{f}\left(\mathrm{e}_{\mathrm{t}}^{*}\right)+\varepsilon_{\mathrm{t}}\right) \mathrm{f}^{\prime}\left(\mathrm{e}^{*} \mathrm{t}\right)\right]
\end{aligned}
$$

Proof: See the Appendix.

Condition (10a) represents consumption smoothing: discounted marginal utilities of consumption are equal over time. Condition (10b) tells us that B equates marginal disutility of effort at $\mathrm{t}$ with the marginal expected utility that higher effort gives him through higher payment and consumption at $\mathrm{t}+1$.

Using (9b) and (10b), one gets the desired comparative static results regarding B's optimal choice of an effort policy. These are all derived in the Appendix:

$$
\begin{aligned}
& \partial \mathrm{e}^{*}{ }_{\mathrm{t}} / \partial\left(\mathrm{S}_{\mathrm{t}}+\mathrm{v}_{\mathrm{t}}(\cdot)\right)<0, \\
& \partial \mathrm{e}_{\mathrm{t}}^{*} / \partial \mathrm{v}_{\mathrm{t}+1}^{\prime}(\cdot)>0,
\end{aligned}
$$




$$
\begin{aligned}
& \partial \mathrm{e}_{\mathrm{t}}^{*} / \partial \sigma_{\varepsilon}{ }^{2}>0, \\
& \partial \mathrm{e}_{\mathrm{t}}{ }_{\mathrm{t}} / \partial \beta>0, \text { and } \\
& \partial \mathrm{e}^{*} \mathrm{t} / \partial \mathrm{R}<0
\end{aligned}
$$

Inequality (11a) subsumes the basic incentive problem created by this contractual structure. Because B's current assets or cumulative payments $\mathrm{S}_{\mathrm{t}}+\mathrm{v}_{\mathrm{t}}(\cdot)$ are entirely determined by past considerations, his current effort is negatively related to the level of these assets. Therefore, the larger the value of his assets, the less money he will need to finance future consumption, which diminishes the incentive to expend effort. ${ }^{19}$ Condition (11b) indicates that B's optimal choice of effort is positively related to the marginal incentive built into the contract. This marginal incentive acts as a delayed piece rate because the better job B does today, the more he will be paid tomorrow. Thus, the more closely B's future payment is tied to his performance, the higher the current effort he will exert, thereby inducing higher expected consumption.

The effect of uncertainty is summarized in $(11 \mathrm{c})$, which tells us that the less reliable $\mathrm{y}_{\mathrm{t}}$ is as a signal of $e_{t}$, i.e., the higher $\sigma_{\varepsilon}^{2}$, the more effort the risk-averse boxer will expend. When a boxer expects to face highly uncertain circumstances his best response is to hedge by stepping up his preparation for the fight. Finally, (11d) and (11e) reflect the effects of the discount factor and gross rate of return on optimal effort. A higher discount factor (lower discount rate) increases the relative importance of tomorrow's consumption on B's payoff so that more effort is induced. A higher rate of return acts similarly: given any amount of savings, a lower effort will be required to induce the same expected income and consumption in period $\mathrm{t}+1$.

As pointed out before, (10b) implies that the payment scheme has counteracting effects on B's choice of effort in the current period: a negative effect of effort disutility, and a positive effect of 
future expected consumption utility. However, because B saves, he needs not rely on his effort alone to enjoy higher future consumption, i.e., savings act as insurance. As a result, it is possible that at some point in time, effort disutility may outweigh expected consumption utility and the boxer may exert arbitrarily low effort. This follows from combining (10b) and (9b), and considering the case where effort non-negativity constraint binds. A corner solution on effort --e ${ }_{t}^{*}(\cdot)$ _0-- implies that:

$$
\mathrm{d}^{\prime}(0)>\beta \mathrm{E}_{\mathrm{t}}\left\{\mathrm{u}^{\prime}\left[\mathrm{R}\left(\mathrm{S}_{\mathrm{t}}+\mathrm{v}_{\mathrm{t}}(\cdot)-\mathrm{c}_{\mathrm{t}}^{*}\right)+\mathrm{v}_{\mathrm{t}+1}(\varepsilon \mathrm{t})-\mathrm{s}_{\mathrm{t}+1}^{*}\right] \mathrm{v}^{\prime}{ }_{\mathrm{t}+1}(\varepsilon \mathrm{t}) \mathrm{f}^{\prime}(0)\right\}
$$

Condition (12) states that B will exert arbitrarily low effort at t if the marginal disutility from expending a small amount of effort exceeds his discounted expected marginal utility from consuming out of current savings and a random future payment. This likely arises from the interaction of high effort-aversion --high $\mathrm{d}^{\prime}--$ and high level of savings --low $\mathrm{u}^{\prime}$. Poor training discipline coupled with large accumulated assets increase the probability of a poor preparation and performance.

Empirically, we observe the above phenomenon when a boxer builds up to the point where he gets his "big payday" and then decides to shirk and not train properly for a subsequent fight. As suggested before, two scenarios are possible. First, the boxer may decide to retire after his big payday so that the impact of current effort on the future becomes meaningless. Second, a boxer may decide to take a big payday with little effort, temporarily lay-off and enjoy his savings, and then come back. Short-term fan memory makes this scenario admissible, because the consequences of a poor performance may be erased by a good performance in the future. Panamanian boxer Roberto "Mano de Piedra" Durán, with his many pugilistic reincarnations, exemplifies this kind of behavior. 
It would be unfair to conclude this section by exclusively mentioning anecdotal evidence on moral hazard in professional boxing. Intertemporal incentives, even if sub-optimal, are capable of eliciting strong effort under some conditions. Clearly, if a boxer has good training discipline and/or his big payday still lies ahead of him, incentives for hard work are significant.

\section{The Fans' Behavior}

The previous section analyzed a boxer's optimal decisions given a payment scheme offered by the fans through the promoter. In an ordinary principal-agent model one would now analyze the principal's strategic choice of a payment scheme using backward induction. However, because fight buyers are heterogeneous and make decisions in isolation, their aggregate behavior will not necessarily mimic that of a strategic principal. Hence, full-fledged backward induction may not be applicable, and systematic ex-post inconsistencies between expected and realized boxers' performances may result.

To illustrate the above point, suppose that there are two kinds of boxing fans. "Avid" fans are those who are more informed and knowledgeable, and process all of the information available just as a strategic principal would. This is, they anticipate possible disincentive effects associated with large guaranteed purses, and determine their willingness to pay accordingly. On the other hand, "casual" fans may not gather and/or carefully process all of the information available prior to the fight. As such, they may fail to account for purse information, and the potential disincentives associated with them.

In this context, the mix of avid and casual fans would be crucial in determining the likelihood that a promoter will offer a given purse. If the bulk of the fans interpreted a very large purse as 
being negatively correlated with the boxer's expected performance, this purse will not be offered because it would lower the market value of the fight and increase the promoter's risk. Hence, with mostly avid fans, promoters would be less likely to offer very large purses in equilibrium. Conversely, if casual fans were a significant fraction of the total fan population, promoters could afford to offer large purses in equilibrium, as they will not hurt the market value of the fight or increase promoter's risk. These results are summarized in the following proposition:

Proposition 2: The boxers' purses (a) reflect the fans' assessments of the information content of these purses, and (b) are inversely related to the fraction of avid fans relative to the total fan population.

Proof: Available upon request.

The idea of a market outcome resulting from the interaction of different categories of agents is associated with the notion of "strategic complementarities" (Haltiwanger and Waldman 1985). A strategic complementarity arises when the higher the total number of agents choosing a particular behavior, the higher the return to a single agent that chooses that behavior.

The strategic complementarity in the boxing market is asymmetric and unexploited. The casual fan would be better-off acting as an avid one but not vice versa. If all fans acted in a more avid-like fashion, the boxer's pay schedule would carry more incentives, and more efficient outcomes could be attained. If avid fans are often disappointed, just like the casual, it is not because the former imitate the latter. Rather, even if the avid fans recognize the externality the casual fans 
impose on them, buying the fight may be a best response if the net expected utility from viewing is positive. This may happen if the fan attaches high utility to a good outcome, even with a high probability of a bad outcome. Likely, avid fans are more likely to derive high utilities from viewing fights so that, even when anticipating the disincentive effect of a large purse, their willingness to pay for the fight may exceed that one of a casual fan. Finally, since fans' entertainment portfolios are likely well-diversified, the risk of viewing a single fight would not meaningfully affect overall exposure.

\section{Some Suggestive Evidence}

Unfortunately, a direct test of the wealth-disincentive proposition is not possible with the available data. This is because of a lack of systematic purse data across a variety of boxers and fights. Purse information is generally available only for "big time" fights, which would result in a sample selection bias if used to test the purse-effort incentive link. The reason is that young fighters or fighters in less prestigious weight categories, for whom reputation building incentive effects are strong, would be excluded from the sample.

However, beyond the purely anecdotal, one can exploit a well-known fact regarding championship boxing purses to indirectly analyze the predictions of the theory. It is known that there is wide variation in championship purses across weight categories, with the higher-weight boxers often taking substantially larger purses than the lower-weight ones. As a result, one expects a newly crowned heavyweight champion to be wealthier than a newly crowned lighter-weight champion, and that the former's wealth will increase faster than the latter's as they successfully defend their titles. Hence, the theoretical prediction that high wealth deters effort would suggest 
that, ceteris paribus, lighter-weight champions will likely exert more effort and hence tend to successfully defend their titles more than heavier weight champions. ${ }^{21}$

Table I presents summary statistics of the performances of professional boxing champions in the eight traditional weight categories. ${ }^{22}$ The performance indices selected are successful title defenses and total months of championship tenure. Since there is variation in frequency of title defenses, this table also presents the average interval between defenses as well as the number of successful defenses per year. Mean difference tests across pairs of weight categories indicate that there are not any significant differences in the performance indicators of heavyweights $(\mathrm{H})$ and light heavyweights (LH). Thus, these two categories (the "big" fighters) are grouped together for purposes of comparison with other weight classes. ${ }^{23}$ The rest of the weight classes can either be pooled together or split between "medium" size fighters (middleweights [M] and welterweights [W]) and "small" fighters (lightweights [L], featherweights [F], bantamweights [B], and flyweights [Fl]). Neither of these groupings has a meaningful impact in their comparison with $\mathrm{H}$ and LH.

(Tables I and II about here)

The z-statistics for mean comparison of performances across weight groups are also presented in Table I. Although we observe that $\mathrm{H}$ and LH tend to keep their titles longer, they do not make significantly more successful defenses than other boxers. The fact that $\mathrm{H}$ and LH enjoy a longer average championship tenure than the rest appears to contradict the wealth-disincentive prediction. However, this inference is refuted in column 3: $\mathrm{H}$ and LH keep their titles longer because they wait significantly longer between defenses than boxers in the other categories. This is the first indication 
of a wealth-disincentive effect in professional boxing. Since $\mathrm{H}$ and LH likely have higher and steeper earning profiles, they do not have the incentive to exert a lot of effort to accumulate extra wealth at shorter intervals. A competing explanation for this longer lag between title fights is that heavier boxers suffer more severe punishment and thus take longer to heal. This explanation is not convincing, because opponents are evenly matched in terms of weight. As such, there should be little or no reason for the relative damage inflicted to significantly vary across categories. In fact, one could argue that lighter fighters are more likely to take longer to heal between fights because of their physically draining efforts to adhere to weight limits. ${ }^{24}$ Anecdotal evidence shows that most of the fatalities associated with boxing have occurred in non-heavyweight fights. ${ }^{25}$

Finally, the observed longer tenure of $\mathrm{H}$ and LH is misleading because (a) the length of tenure indicator has a very large variance due to the presence of a few outliers (see Table II), and (b) the quality of opposition for champions in the heavier-weight classes has traditionally been lower than the one for champions in other divisions. ${ }^{26}$

The previous discussion points towards the use of a more standard measure to compare performance across weight categories. Column 4 shows the number of successful defenses per year for each grouping of weight divisions. It is clear that $\mathrm{H}$ and $\mathrm{LH}$ tend to make significantly fewer successful defenses per year than the rest. However, since this test penalizes weight classes in which boxers tend to keep their titles longer, I re-evaluated these comparisons by omitting the outliers in each of the weight classes. As seen in Table II, omitting the two highest and the two lowest performance indicators in each class diminishes the significance of the tests in columns 1 and 2 (absolute measures), but leaves the significance of the standard tests in columns 4 and 5 basically unchanged. Thus, the tests shown in the last two columns appear more robust and reliable than the 
ones in the first two columns. Similar results hold if omitting only the highest and lowest indicators in each group.

In sum, the main indications of the wealth-disincentive effect in professional boxing are the longer interval between defenses and the fewer successful defenses per year observed in the heavier --and wealthier-- weight categories. Lower-weight boxers, facing lower and flatter earnings profiles, have the incentive to exert more effort and successfully defend their titles more often to build-up their savings towards retirement. Heavier boxers can afford to be less active --and less successful-and still be able to retire or voluntarily lay-off after a few large paydays.

\section{Concluding Remarks}

An important result in the agency literature is that second-best solutions are attainable under reward systems involving optimal risk-sharing and a constrained level of incentives. Unlike most other individual sports, the reward system in professional boxing specifies a boxer's payment as a function of past performance alone. This paper has argued that this system, while emphasizing the role of insurance, provides work incentives that may be sub-optimal. By detaching the boxer's current reward from his current performance, these contracts do not make use of a valuable signal of the boxer's unobservable effort in preparing for a fight.

Boxing is a rough and risky sport and as such providing insurance is very important. Any fighter's life could be lost in a single fight. However, even in the presence of such risks, existing incentives leave a lot to be desired. This fact, compounded with the growth of purses for boxing "superstars", makes "Buster" Douglas-like episodes ever more likely to occur. Preventing such episodes does not seem easy. Since a fan association or union does not exist, it is not feasible to 
expect that provision of incentives will come from this front.

Can fans rely on the boxing organizations or athletic commissions to provide appropriate incentives? The answer to this question appears to be, once again, negative. Unlike other sports, boxing has a multiplicity of sanctioning organizations, and the athletic commissions are virtually powerless relative to the promotional and business ventures. This multiplicity of organizations and promoters creates a propitious environment for poor incentive provision. If a promoter offered a boxer a contract with heavy incentives, risk-aversion would imply that the boxer would prefer a contract offered by a different promoter specifying more insurance and fewer incentives. From the principal-agent literature, we know that in these environments the agents are bound to enjoy more favorable contracting terms.

The contrast between the organizational structures and reward systems in boxing and other individual sports like tennis, golf, or bowling, suggests what could be an appealing improvement of the current incentive system in boxing. The common denominators across these other sports are that they all (a) have fairly centralized governing bodies, and (b) display tournament-based compensation schemes. If applied to boxing, the tournament idea would mean that given a total purse amount, the winner would be awarded a larger fraction than the loser. While providing insurance through guaranteeing a minimum amount, this system would certainly have more desirable incentive properties than the current one (see Lazear and Rosen 1981). Unfortunately, without a major institutional overhaul, a change in this direction will never make it beyond the avid fan's wish list. 


\section{Table I}

Performance Indicators of Professional Boxing Champions

(from start of Queensberry Rules to May 1994), and z-statistics for Tests of Mean Differences of the Indicators between Weight Groups

(Full sample)

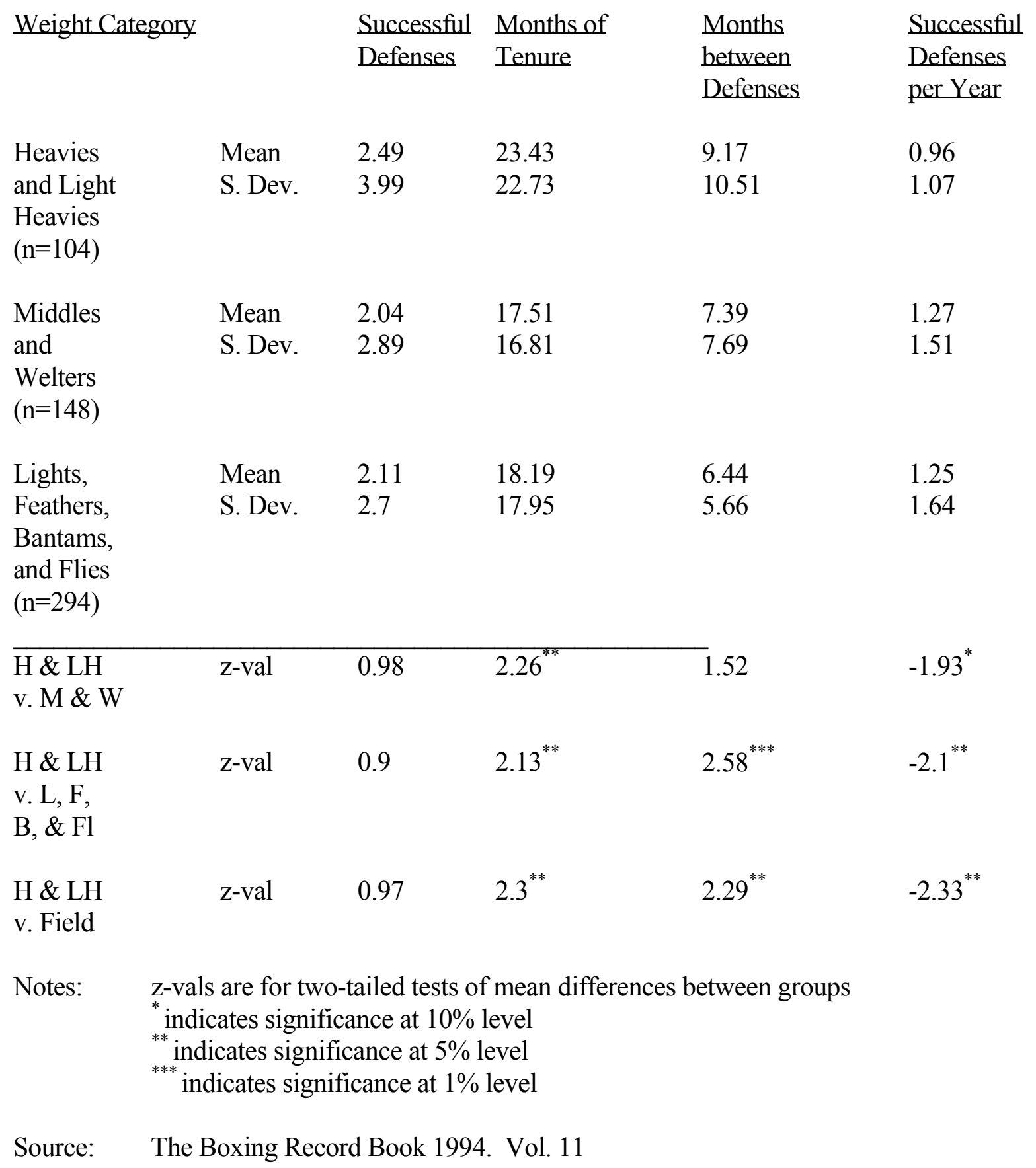




\section{Table II}

\section{Performance Indicators of Professional Boxing Champions}

(from start of Queensberry Rules to May 1994), and z-statistics for Tests of Mean Differences of the Indicators between Weight Groups

(Two highest and two lowest performance indicators omitted in each weight class)

\begin{tabular}{|c|c|c|c|c|c|}
\hline Weight $\mathrm{Ca}$ & egory & $\begin{array}{l}\text { Successful } \\
\text { Defenses }\end{array}$ & $\begin{array}{l}\text { Months of } \\
\text { Tenure }\end{array}$ & $\begin{array}{l}\text { Months } \\
\text { between } \\
\text { Defenses }\end{array}$ & $\begin{array}{l}\text { Successful } \\
\text { Defenses } \\
\text { per Year }\end{array}$ \\
\hline $\begin{array}{l}\text { Heavies } \\
\text { and Light } \\
\text { Heavies } \\
(\mathrm{n}=96)\end{array}$ & $\begin{array}{l}\text { Mean } \\
\text { S. Dev. }\end{array}$ & $\begin{array}{l}2.06 \\
2.85\end{array}$ & $\begin{array}{l}19.96 \\
18.02\end{array}$ & $\begin{array}{l}7.6 \\
5.35\end{array}$ & $\begin{array}{l}0.97 \\
1.06\end{array}$ \\
\hline $\begin{array}{l}\text { Middles } \\
\text { and } \\
\text { Welters } \\
(\mathrm{n}=140)\end{array}$ & $\begin{array}{l}\text { Mean } \\
\text { S. Dev. }\end{array}$ & $\begin{array}{l}1.76 \\
2.11\end{array}$ & $\begin{array}{l}15.78 \\
14.97\end{array}$ & $\begin{array}{l}6.71 \\
5.67\end{array}$ & $\begin{array}{l}1.24 \\
1.44\end{array}$ \\
\hline $\begin{array}{l}\text { Lights, } \\
\text { Feathers, } \\
\text { Bantams, } \\
\text { and Flies } \\
(\mathrm{n}=278)\end{array}$ & $\begin{array}{l}\text { Mean } \\
\text { S. Dev. }\end{array}$ & $\begin{array}{l}1.93 \\
2.19\end{array}$ & $\begin{array}{l}16.66 \\
15.59\end{array}$ & $\begin{array}{l}5.87 \\
3.6\end{array}$ & $\begin{array}{l}1.27 \\
1.65\end{array}$ \\
\hline $\begin{array}{l}\text { H \& LH } \\
\text { v. M \& W }\end{array}$ & z-val & 0.90 & $1.88^{*}$ & 1.26 & $-1.7^{*}$ \\
\hline $\begin{array}{l}\text { H \& LH } \\
\text { v. L, F, } \\
\text { B, \& Fl }\end{array}$ & z-val & 0.42 & 1.61 & $3.03^{* * *}$ & $-2.1^{* *}$ \\
\hline $\begin{array}{l}\text { H \& LH } \\
\text { v. Field }\end{array}$ & z-val & 0.62 & $1.823^{*}$ & $2.53^{* *}$ & $-2.23^{* *}$ \\
\hline Notes: & $\begin{array}{l}\text { z-vals are for } \mathrm{t} \\
{ }^{*} \text { indicates sign } \\
{ }^{* *} \text { indicates sign } \\
{ }^{* * *} \text { indicates sig }\end{array}$ & $\begin{array}{l}\text { iled tests o } \\
\text { ice at } 10 \% \\
\text { nce at } 5 \% \\
\text { ance at } 1 \%\end{array}$ & $\begin{array}{l}\text { mean differ } \\
\text { level } \\
\text { evel } \\
\text { level }\end{array}$ & etween groups & \\
\hline
\end{tabular}

Source: The Boxing Record Book 1994. Vol. 11 


\section{Appendix}

\section{Proof of Proposition 1}

The problem defined in (9a)-(9e) is a recursive stochastic dynamic program for which a well-behaved value function $\mathrm{V}\left[\mathrm{S}_{\mathrm{t}}, \mathrm{V}_{\mathrm{t}}(\cdot)\right]$ exists (see Sargent 1987). Bellman's functional equation is:

$$
\begin{gathered}
\mathrm{V}\left[\mathrm{S}_{\mathrm{t}, \mathrm{V} t}\left(\mathrm{f}\left(\mathrm{e}_{\mathrm{t}-1}\right)+\varepsilon_{\mathrm{t}-1}\right)\right]= \\
\underset{\mathrm{S}_{\mathrm{t}}, \mathrm{e}_{\mathrm{t}}}{\operatorname{Max}}\left\{\mathrm{u}\left[\mathrm{S}_{\mathrm{t}}+\mathrm{v}_{\mathrm{t}}\left(\mathrm{f}\left(\mathrm{e}_{\mathrm{t}-1}\right)+\varepsilon_{\mathrm{t}-1}\right)-\mathrm{s}_{\mathrm{t}}\right]-\mathrm{d}\left(\mathrm{e}_{\mathrm{t}}\right)+\beta \mathrm{E}_{\mathrm{t}} \mathrm{V}\left[\mathrm{S}_{\mathrm{t}+1}, \mathrm{~V}_{\mathrm{t}+1}\left(\mathrm{f}\left(\mathrm{e}_{\mathrm{t}}\right)+\varepsilon_{\mathrm{t}}\right)\right]\right\},
\end{gathered}
$$

where $\mathrm{S}_{\mathrm{t}}=\mathrm{Rs}_{\mathrm{t}-1}$ are B's gross savings at the beginning of period $\mathrm{t}$, and $\mathrm{s}_{\mathrm{t}}=\mathrm{S}_{\mathrm{t}}+\mathrm{v}_{\mathrm{t}}\left(\mathrm{f}\left(\mathrm{e}_{\mathrm{t}-1}\right)+\varepsilon_{\mathrm{t}-1}\right)-\mathrm{c}_{\mathrm{t}}$ represents his savings at $t$. The transition equation for B's savings is $\mathrm{S}_{\mathrm{t}+1}=\mathrm{Rs}$. Since the random variables $\varepsilon$ are i.i.d. over time, the transition probabilities for these variables are also well-defined. The state variables are B's gross savings $\mathrm{S}_{\mathrm{t}}$ and his current payment $\mathrm{v}_{\mathrm{t}}(\cdot)$, which is based in his last period's effort. The control variables are his effort level $\left(e_{t}\right)$ and his savings $\left(s_{t}\right)$ at period t. From the definition of savings, a choice of $\mathrm{s}_{\mathrm{t}}$ automatically implies a choice of $\mathrm{c}_{\mathrm{t}}$.

Since $\mathrm{u}($.$) is concave and \mathrm{d}(\cdot)$ is convex the current-period return $[\mathrm{u}(\cdot)-\mathrm{d}(\cdot)]$ is concave and bounded, and it is also clear that the constraint set is compact and convex. Thus, if we start from any bounded and continuous $\mathrm{V}_{0}$, the necessary and sufficient conditions for a unique interior maximum at the time-invariant policies $\left\{\mathrm{c}^{*}{ }_{\mathrm{t}}\left[\mathrm{S}_{\mathrm{t}}, \mathrm{V}_{\mathrm{t}}(\cdot)\right], \mathrm{e}^{*}{ }_{\mathrm{t}}\left[\mathrm{S}_{\mathrm{t}}, \mathrm{V}_{\mathrm{t}}(\cdot)\right]\right\}$ are:

$$
\begin{aligned}
& \mathrm{u}^{\prime}\left(\mathrm{c}_{\mathrm{t}}^{*}\right)-\beta \operatorname{RE}_{\mathrm{t}}\left(\partial \mathrm{V} / \partial \mathrm{S}_{\mathrm{t}+1}\right)\left[\mathrm{S}_{\mathrm{t}+1}, \mathrm{~V}_{\mathrm{t}+1}\left(\mathrm{f}\left(\mathrm{e}_{\mathrm{t}}^{*}\right)+\varepsilon \mathrm{t}\right)\right]=0 \\
& -\mathrm{d}^{\prime}\left(\mathrm{e}_{\mathrm{t}}^{*}\right)+\beta \mathrm{RE}_{\mathrm{t}}\left(\partial \mathrm{V} / \partial \mathrm{v}_{\mathrm{t}+1}\right)\left[\mathrm{S}_{\mathrm{t}+1}, \mathrm{~V}_{\mathrm{t}+1}\left(\mathrm{f}^{*}\left(\mathrm{e}_{\mathrm{t}}^{*}\right)+\varepsilon_{\mathrm{t}}\right)\right] \mathrm{v}_{\mathrm{t}+1}\left(\mathrm{f}\left(\mathrm{e}_{\mathrm{t}}^{*}\right)+\varepsilon_{\mathrm{t}}\right) \mathrm{f}^{\prime}\left(\mathrm{e}_{\mathrm{t}}^{*}\right)=0
\end{aligned}
$$

where the arguments of $\mathrm{c}^{*}[\cdot]$ and $\mathrm{e}^{*}[\cdot]$ have been omitted, and will be omitted hereafter.

Since, given the conditions of the problem, the value function is differentiable, using Benveniste and Scheinkman's envelope formula we get:

$$
\left(\partial \mathrm{V} / \partial \mathrm{S}_{\mathrm{t}+1}\right)\left[\mathrm{S}_{\mathrm{t}}, \mathrm{V}_{\mathrm{t}}\left(\mathrm{f}\left(\mathrm{e}_{\mathrm{t}-1}{ }^{*}\right)+{ }_{\mathrm{tt}-1}\right)\right]=\left(\partial \mathrm{V} / \partial \mathrm{V}_{\mathrm{t}+1}\right)\left[\mathrm{S}_{\mathrm{t}}, \mathrm{V}_{\mathrm{t}}\left(\mathrm{f}\left(\mathrm{e}_{\mathrm{t}-1}\right)+{ }_{\mathrm{t}-1}\right)\right]=\mathrm{u}^{\prime}\left(\mathrm{c}^{*} \mathrm{t}\right)
$$


Combining (A2)-(A4) we get the stochastic Euler equations (10a) and (10b).

\section{Comparative Statics from Proposition 1}

The interest is on the comparative statics involving the optimal effort policy, showed in (11a)-(11e). Using B's savings transition equation and the stochastic Euler equation (10b) yields:

$$
\begin{gathered}
\mathrm{d}^{\prime}\left(\mathrm{e}_{\mathrm{t}}^{*}\right)-\beta \mathrm{E}_{\mathrm{t}}\left\{\mathrm{u}^{\prime}\left[\mathrm{R}\left(\mathrm{S}_{\mathrm{t}}+\mathrm{v}_{\mathrm{t}}\left(\mathrm{f}\left(\mathrm{e}^{*}{ }_{\mathrm{t}-1}\right)+{ }_{\varepsilon \mathrm{t}-1}\right)-\mathrm{c}^{*} \mathrm{t}\right)+\mathrm{v}_{\mathrm{t}+1}\left(\mathrm{f}\left(\mathrm{e}^{*}{ }_{\mathrm{t}}\right)+\varepsilon_{\mathrm{t}}\right)-\mathrm{s}_{\mathrm{t}+1}^{*}\right] \times\right. \\
\left.\left[\mathrm{v}^{\prime} \mathrm{t}+1\left(\mathrm{f}\left(\mathrm{e}^{*} \mathrm{t}\right)+{ }_{\mathrm{tt}}\right) \mathrm{f}^{\prime}\left(\mathrm{e}^{*} \mathrm{t}\right)\right]\right\}=0
\end{gathered}
$$

Let us denote $(A 5)$ as $G\left(e^{*}, z\right)=0$, where $\mathrm{z}=\left(\mathrm{z}_{1}, \ldots, \mathrm{Zn}_{\mathrm{n}}\right)$ is a vector of variables other than $\mathrm{e}^{*}$. Then, the comparative static results will be of the form:

$$
\partial e^{*} / \partial z_{i}=-\partial G / \partial z_{i} / \partial G / \partial e^{*}, i=1, \ldots, n
$$

Hence, the denominator of all the expressions in (11a)-(11e) is the same, and omitting all arguments, it is equal to:

$$
\begin{gathered}
\mathrm{D}=\mathrm{d}^{\prime \prime}(.)-\beta \mathrm{E}_{\mathrm{t}}\left\{\mathrm{u}^{\prime \prime}(\cdot)\left[\mathrm{v}^{\prime} \mathrm{t}+1(\cdot) \mathrm{f}^{\prime}(.)-\left(\partial \mathrm{s}^{*}{ }_{\mathrm{t}+1} / \partial \mathrm{e}^{*} \mathrm{t}\right)\right] \mathrm{v}_{\mathrm{t}+1}^{\prime}(.) \mathrm{f}^{\prime}(.)+\right. \\
\left.\mathrm{u}^{\prime}(\cdot)\left[\mathrm{v}^{\prime \prime}{ }_{\mathrm{t}+1}(.) \mathrm{f}^{\prime}(\cdot)+\mathrm{v}_{\mathrm{t}+1}^{\prime}(\cdot) \mathrm{f}^{\prime \prime}(\cdot)\right]\right\}
\end{gathered}
$$

Since $\partial \mathrm{s}_{\mathrm{t}+1}^{*} / \partial \mathrm{e}_{\mathrm{t}}^{*}=\mathrm{v}_{\mathrm{t}+1}^{\prime}(\cdot) \mathrm{f}^{\prime}(\cdot)-\partial \mathrm{c}^{*}{ }_{\mathrm{t}+1} / \partial \mathrm{e}_{\mathrm{t}}{ }_{\mathrm{t}}$, the above expression is always positive.

Expression (11a) is equal to:

$$
\partial \mathrm{e}^{*} \mathrm{t} / \partial\left(\mathrm{S}_{\mathrm{t}}+\mathrm{v}_{\mathrm{t}}(\cdot)\right)=-\left\{\left[\partial \mathrm{G} / \partial\left(\mathrm{S}_{\mathrm{t}}+\mathrm{v}_{\mathrm{t}}(\cdot)\right)\right] / \mathrm{D}\right\}
$$

The numerator of the right-hand-side (RHS) of (A8) is equal to:

$$
-\beta \mathrm{E}_{\mathrm{t}}\left\{\mathrm{u}^{\prime \prime}(\cdot) \mathrm{Rv}_{\mathrm{t}+1}^{\prime}(\cdot) \mathrm{f}^{\prime}(\cdot)\right\}>0
$$

Thus $\partial \mathrm{e}^{*}{ }_{\mathrm{t}} / \partial\left[\mathrm{S}_{\mathrm{t}}+\mathrm{v}_{\mathrm{t}}(\cdot)\right]<0$.

Expression (11b) is equal to:

$$
\partial \mathrm{e}^{*}{ }_{\mathrm{t}} / \partial \mathrm{v}^{\prime}{ }_{\mathrm{t}+1}(\cdot)=-\left\{\left[\partial \mathrm{G} / \partial \mathrm{v}^{\prime} \mathrm{t}+1(\cdot)\right] / \mathrm{D}\right\}
$$

The numerator of the RHS of (A9) is equal to: 
(A9')

$$
-\beta \mathrm{E}_{\mathrm{t}}\left\{\mathrm{u}^{\prime}(\cdot) \mathrm{f}^{\prime}(\cdot)\right\}<0
$$

Thus, $\partial \mathrm{e}^{*}{ }_{\mathrm{t}} / \partial \mathrm{v}^{\prime}{ }_{\mathrm{t}+1}(\cdot)>0$.

Expression (11c) is equal to:

$$
\partial \mathrm{e}^{*} \mathrm{t} / \partial \sigma_{\varepsilon}{ }^{2}=-\left\{\left[\partial \mathrm{G} / \partial \sigma_{\varepsilon}{ }^{2}\right] / \mathrm{D}\right\}
$$

The numerator of the RHS of (A10) follows from taking a first-order Taylor expansion for the terms inside the expectations operator of (A5):

$$
-\beta\left\{\mathrm{u}^{\prime \prime}(\cdot) \mathrm{v}^{\prime \prime}{ }_{\mathrm{t}+1}(\cdot)\left[\mathrm{f}^{\prime}(\cdot)\right]^{2}\right\}<0
$$

Thus $\partial \mathrm{e}^{*} \mathrm{t} / \partial \sigma_{\varepsilon}{ }^{2}>0$.

Expression (11d) is equal to:

$$
\partial \mathrm{e}^{*}{ }_{\mathrm{t}} / \partial \beta=-\{[\partial \mathrm{G} / \partial \beta] / \mathrm{D}\}
$$

The numerator of the RHS of (A11) is equal to:

$$
-\mathrm{E}_{\mathrm{t}}\left\{\mathrm{u}^{\prime}(.) \mathrm{v}^{\prime}(.) \mathrm{f}^{\prime}(.)\right\}<0
$$

Thus $\partial \mathrm{e}^{*} / \partial \beta>0$.

Finally, expression (11e) is equal to:

$$
\partial \mathrm{e}^{*} \mathrm{t} / \partial \mathrm{R}=-\{[\partial \mathrm{G} / \partial \mathrm{R}] / \mathrm{D}\}
$$

The numerator of the RHS of (A12) is equal to:

$$
-\beta \mathrm{E}_{\mathrm{t}}\left\{\mathrm{u}^{\prime \prime}(\cdot) \mathrm{s}^{*} \mathrm{t}\right\}>0
$$

Thus $\partial \mathrm{e}^{*}{ }^{\mathrm{t}} / \partial \mathrm{R}<0$. 


\section{Notes}

${ }^{1}$ There are cases where a boxer shares revenues with a promoter above a guaranteed amount. The amount to be shared, called the "overage", is uncertain and depends on possible extra pay-per-view or closed-circuit proceeds. Although this kind of agreement results in a riskier purse, the reward still is performance-independent. See Reed (1981) for a description of compensation practices in professional boxing.

${ }^{2}$ A first-best solution is attainable if the agent's output is a deterministic function of his effort. Here, if the agent is paid his marginal product he will be induced to perform optimally. With unobservable effort and output subject to random shocks, a first best is still attainable if both principal and agent are risk-neutral. Because risk-sharing is not an issue, a piece rate will elicit optimality. If the agent is risk-averse, there is a conflict between risk-sharing and incentives and only second-best outcomes are attainable. Here, the optimal reward schedule consists of a state-independent payment, which provides the agent with insurance, and an output dependent payment, which provides incentives. The partial insurance results in optimal risk-sharing but creates moral hazard. See Stiglitz (1975), Mirrlees (1976), Hart and Holmström (1987), and Sappington (1991) for extended discussions.

${ }^{3}$ Bizer and DeMarzo (1991) obtain the opposite result. In a model with risky debt, they find an equilibrium in which an agent borrows in the first period and defaults on his debt with positive probability. Harris and Holmström (1982) discuss the implications of introducing risky debt in a multi-period agency model.

4 The November 12, 1992 edition of The New York Times, quotes pay-per-view boxing businessman Seth Abraham as saying "The one beautiful thing about this business is that the viewer has a short memory,..., looking at it event by event. If an event warrants the time and the money, they'll order".

${ }^{5}$ The focus of the paper is not on contract design. The model is based on observed institutional features, and the goal is to analyze the behavior of the involved parties that is consistent with these features. The reader interested in contract design under similar conditions should refer to the references cited earlier in this section.

${ }^{6}$ Revenue sources include television, closed circuit and on-site proceeds, sponsoring fees, sale of memorabilia, and others.

${ }^{7}$ A boxing fight has club good characteristics. This is due to price excludability and non-rivalry of consumption. Combined with a monopolistic situation, it is obvious that pricing of the viewing fees will not be efficient. This means that some unsatisfied demand will remain at the posted fees even though serving one more viewer entails zero marginal cost. See Cornes and Sandler (1986), Ch. 4.

${ }^{8}$ The promoter's role is twofold. First, he contracts with the interested parties, organizes events, advertises the fight, and coordinates with managers and athletic commissions. For these services, he charges a promotional fee proportional to the fight's expected proceeds net of promotional costs. 
With competing promoters, it is reasonable to assume that the promotional fee results from market conditions. In fact, it is customary for promoters to bid for the right to promote a fight. Second, he assesses the fight's market value and guarantees payments to the boxers based on this assessment. Thus, he plays an insurance role, and assumes the risk arising from uncertain ex-post fight revenues. Despite this insurance role, the promoter is not a "principal" as defined in the agency literature. He is basically an intermediary between boxers and fight buyers. This intermediation role is consistent with the fact that some boxers have chosen to promote their own fights.

${ }^{9}$ Since B has no control over A's reputation, this factor will impose an externality --positive or negative-- over B's purse .

${ }^{10}$ I use this simple output formulation for clarity's sake. A straightforward extension including innate abilities would leave the main results unchanged.

${ }^{11}$ Convex effort disutility is conventional in this kind of problem. In boxing, this convexity is clear-cut because the demands of training regimes are severe. These include getting up early to do road work, strict diets, several hours of conditioning and sparring, etc. For lighter-weight fighters, the effort required to keep their weight within the limit can be tremendous.

${ }^{12}$ See Chapter 9 of Fudenberg and Tirole (1991).

${ }^{13}$ Lazear (1979) argues that with increasing age-earnings profiles, termination of employment should be mandatory, because marginal products will most likely fall below pay at the later stages in the career. Gibbons and Murphy (1992) show that in the presence of career concerns, an optimal contract deals with the end-game problem by introducing stronger explicit incentives as retirement nears.

14 The proliferation of sports media through cable and satellite television as well as the Internet, has made information more readily accessible to sports fans. The main results we present in the next section will rely on the fans' ability to process the information rather than the amount of information itself.

${ }^{15}$ Once again, Buster Douglas' case is the typical example of the fans' limited recall. Douglas was guaranteed his \$20 million purse based exclusively on his win over Mike Tyson. Fans did not seem to remember that he had quit lying against the ropes in his first title attempt against Tony Tucker in 1987. Other previous defeats at the hands of mediocre opposition and erratic conditioning patterns were also overlooked.

${ }^{16}$ The time index in this summation refers to the time elapsing between fights and not necessarily to any calendar period. Without loss of generality one could alternatively assume that a fixed period elapses between fights. In addition, the problem could be reinterpreted as one with a finite but unknown horizon.

17 The problem's formulation could be amended in a number of ways that would not affect its 
recursive nature. First, the boxer's strategy could also include the choice of an opponent. After the opponent has been chosen, consumption and effort would then be conditional on the opponent's reputation. Second, the fans recall could be lengthened by making the boxer's payment a function of his whole reputation. In this case, the problem would include a transition equation for the reputation in which the most recent performance would likely carry a higher weight than the previous ones. These extensions yield results qualitatively similar to the ones presented here. Holsmtröm 1982 considers a model with learning on the demand side.

${ }^{18}$ Sargent (1987) gives the conditions under which the intertemporal problem has a stationary representation. See also Yaari (1975) for the derivation of the value function and optimal consumption policy using a similar framework.

${ }^{19}$ Suppose that, B's probability of winning a fight depends positively on his training effort. Then it follows that, ceteris paribus, B's probability of winning is inversely related to his purse.

${ }^{20}$ A sign of poor training habits is a wide fluctuation of the fighter's weight between and across fights. Boxers like Douglas, Durán, and James Toney have been known to follow this pattern. Unfortunately, information about the boxers' weights between fights is seldom available, and weight profiles across fights is only observable in heavyweights.

${ }^{21}$ The use of data of championship bouts only potentially biases the results I present. This is because purses in championship bouts are most of the time larger that in non-championship fights. As such, the purse disincentive effect may be larger when it comes to championships (relative to nonchampionships). However, since the main thrust of the claims will be based on comparing purses across weight categories, the purse-disincentive effect should still appear as it relates to weight rather than fight status.

${ }^{22}$ The champions included are all the ones recognized by at least one major sanctioning association under Queensberry --post-bare-knuckle-- rules up to May 30, 1994. Excluded are champions that gave up their titles without retiring, because this action is likely not prompted by a wealth-disincentive effect. This excluded group consists primarily of champions who move up to challenge heavier-weight titleholders.

${ }^{23}$ An important reason for this grouping is that the sample size for heavyweights alone is too small to yield a statistical test with power. This grouping is also somewhat historically justified, since the light heavyweight category has often been perceived as a "transition" weight class for fighters intending to move to the heavyweight class. Traditionally, the great light heavyweight champions like Bob Fitzimmons, Tommy Loughran, Joey Maxim, Archie Moore, Billy Conn, Bob Foster, Michael Spinks, and Michael Moorer eventually challenged for the heavyweight crown.

${ }^{24}$ In fact, since fighter weigh-ins take place the day before the fight, many fighters dehydrate themselves in order to make the weight, and then proceed to regain a substantial amount in a shortperiod of time. Boxers like Arturo Gatti and James Toney are known for gaining as much as 15 to 20 pounds between the weigh-in and the actual fight time. Needless to say, this may pose significant 
risks both for the fighter gaining the weight as well as his opponent.

${ }^{25}$ High profile cases of permanent impairment/death as a result of injuries suffered in a match include Benny "Kid" Paret (middleweight), Deuk-Koo Kim (lightweight), Michael Watson (middleweight), "Kid" Akeem (bantamweight), Gerald McClellan (super middleweight), and Jimmy García (super feartherweight).

${ }^{26}$ The Ring magazine, in a number of issues between August 1987 and February 1989, published some carefully constructed "quality of opposition" indexes for champions in four of the traditional weight categories. Out of a maximum of 10 points, the averages were 6.926 (heavyweights), 8.071 (light heavyweights), 8.25 (middleweights), and 8.274 (lightweights). Simple observation shows that the opposition gets better as the weight gets lower. In fact, the index for heavyweights is lower than each --as well as the pool-- of all the other categories at a $1 \%$ level of significance. Also, the pool of the two heaviest weight groups has an index significantly lower than the other two weight groups at a $1 \%$ level. 


\section{References}

Allen, F. (1985), "Repeated Principal-Agent Relationships with Lending and Borrowing," Economics Letters 17, 27-31.

Bizer, D. and P. DeMarzo (1991), "Labor Contracts with Banking," Working Paper No. 96, Kellogg Graduate School of Management, Northwestern University.

The Boxing Record Book (1994), Vol. 11, New Jersey, Fight Fax, Inc.

Cornes, R. and T. Sandler (1986), The Theory of Externalities, Public Goods, and Club Goods, Cambridge, Cambridge University Press.

Fama, E. (1980), "Agency Problems and the Theory of the Firm," Journal of Political Economy 88, 288-307.

Fudenberg, D., B. Holmström, and P. Milgrom (1985), "Short Term Contracts and Long Term Agency Relationships," Journal of Economic Theory 51, 1-31.

Fudenberg, D., and J. Tirole (1991), Game Theory, Massachusetts, MIT Press.

Gibbons, Robert, and Kevin Murphy (1992), "Optimal Incentive Contracts in the Presence of Career Concerns," Journal of Political Economy 100, 468-505.

Haltiwanger, J., and M. Waldman (1985), "Rational Expectations and the Limits of Rationality: An Analysis of Heterogeneity," American Economic Review LXXV, 326-340.

Harris, M., and B. Holmström (1982), "A Theory of Wage Dynamics," Review of Economic Studies 49, 315-333.

Hart, O., and B. Holmström (1987), "The Theory of Contracts," in Advances in Economic Theory, ed. by T. Bewley, Cambridge, Cambridge University Press.

Holmström, B. (1979), "Moral Hazard and Observability," Bell Journal of Economics 10, 74-91.

Holmström, B. (1982), "Managerial Incentive Problems-A Dynamic Perspective," in Essays in Economics and Management in Honor of Lars Wahlbeck, Helsinki, Swedish School of Economics.

Klein, B., and K. Leffler (1981), "The Role of Market Forces in Assuring Contractual Performance," Journal of Political Economy 81, 615-641.

Kreps, D., P. Milgrom, J. Roberts, and R. Wilson (1981), "Rational Cooperation in the Finitely Repeated Prisoner's Dilemma," Journal of Economic Theory 27, 45-252. 
Lambert, R. (1983), "Long-Term Contracting and Moral Hazard," Bell Journal of Economics 14, 441-452.

Lazear, E. (1979), "Why is There Mandatory Retirement?," Journal of Political Economy 87, 1261-1284.

Lazear, E., and S. Rosen (1981), "Rank-Order Tournaments as Optimum Labor Contracts," Journal of Political Economy 89, 841-864.

Mirrlees, J. (1976), "The Optimal Structure of Authority and Incentives Within an Organization," Bell Journal of Economics 7, 105-131.

Radner, R. (1981), "Monitoring Cooperative Agreements in a Repeated Principal-Agent Relationship," Econometrica 49, 1127-1148.

Radner, R. (1985), "Repeated Principal-Agent Games with Discounting," Econometrica 53, 1173-1198.

Reed, G. (1981), This Business of Boxing and "Its Secrets", Washington, D.C., and Detroit, New National Publishing Company.

The Ring (various issues 1987-1989), New York, The Ring Publishing Corp.

Rogerson, W. (1985), "Repeated Moral-Hazard," Econometrica 53, 69-76.

Rubinstein, A. and M. Yaari (1983), "Repeated Insurance Contracts and Moral Hazard," Journal of Economic Theory 30, 74-97.

Sappington, D. (1991), "Incentives in Principal-Agent Relationships," Journal of Economic Perspectives 5, 45-66.

Sargent, T. (1987), Dynamic Macroeconomic Theory, Cambridge, MA, Harvard University Press.

Shapiro, C. (1982), "Consumer Information, Product Quality and Seller Reputation, Bell Journal of Economics 13, 20-35.

Shavell, S. (1979), "Risk Sharing and Incentives in the Principal and Agent Relationship," Bell Journal ofEconomics 10, 55-73.

Stiglitz, J. (1975), "Incentives, Risk and Information: Notes Towards a Theory of Hierarchy," Bell Journal of Economics 6, 552-579.

Yaari, M. (1976), "A Law of Large Numbers in the Theory of Consumer's Choice Under Uncertainty," Journal of Economic Theory 12, 202-217. 